debates 


\section{Homenaje a Nicanor Parra (1968) de Jaime Barrios: cine, experimentación y política en el underground latino}

Homenaje a Nicanor Parra (1968) by Jaime Barrios: cinema, experimentation and politics in the Latin underground scene Homenagem a Nicanor Parra (1968) de Jaime Barrios: cinema, experimentação e política no underground latino

\section{Julio Ramos}

UNIVERSIDAD DE CALIFORNIA, BERKELEY, ESTADOS UNIDOS

Profesor Emérito de la Universidad de California, Berkeley. Autor de varios libros sobre literatura y cultura latinoamericana, entre ellos, Desencuentros de la modernidad en América Latina (Fondo de Cultura Económica, 1989) y Sujeto al límite: ensayos de cultura literaria y visual (Monte Ávila, 2011). También ha dirigido varios cortometrajes documentales, entre ellos, Detroit's Rivera. The Labor of Public Art (2017) y Mar Arriba: los conjuros de Silvia Rivera Cusicanqui (2011). Correo electrónico: ramosjuliox@gmail.com 


\section{Resumen}

Este trabajo es una aproximación al filme Homenaje a Nicanor Parra (1968) de Jaime Barrios y su relevancia en las discusiones actuales sobre cine, experimentación y política a fines de la década del sesenta. El trabajo destaca la relación entre el cine expandido de Barrios y la antipoesía de Nicanor Parra en el contexto más amplio de los movimientos contraculturales y de las discusiones que generó la proyección de la película en la Cineteca de la Universidad de Chile en 1968.

Palabras clave: Jaime Barrios;
cine underground; Nicanor
Parra; antipoesía; contracultura;
cine expandido

Palabras clave: Jaime Barrios;

Parra; antipoesía; contracultura

\section{Abstract}

This work is an approach to the film Homenaje a Nicanor Parra (1968) by Jaime Barrios and its relevance in current discussions about cinema, experimentation and politics in the late 1960's. The work highlights the relationship between Barrios cinematic practice and the antipoetry of Nicanor Parra in the broader context of the countercultural movements and the political debates generated by the screening of this film at the Cineteca of the University of Chile in 1968.

Keywords: Jaime Barrios;

Underground cinema; Nicanor Parra; Antipoetry;

Counterculture;

Expanded cinema

\section{Resumo}

Este trabalho é uma aproximação do filme Homenagem a Nicanor Parra (1968), de Jaime Barrios, e a sua relevância nas discussões atuais sobre cinema, experimentação e política no final da década do sessenta. $\mathrm{O}$ trabalho destaca a relação entre o cinema expandido de Barrios e a antipoesia de Nicanor Parra no contexto mais amplio dos movimentos contraculturais e das discussões que a projetação do filme na Cineteca da Universidade de Chile em 1968 gerou.

Palavras-chave: Jaime Barrios; cinema underground; Nicanor Parra; antipoesia, contracultura; cinema expandido

RECIBIDO: 7 DE FEBRERO DE 2017. ACEPTADO: 20 DE MAYO DE 2017. DISPONIBLE EN LÍNEA: 8 DE AGOSTO DE 2018

Cómo citar este artículo:

Ramos, Julio. "Homenaje a Nicanor Parra (1968) de Jaime Barrios: cine, experimentación y política en el underground latino". Cuadernos de Literatura 22.43 (2018): 15-41.https://doi.org/10.11144/Javeriana.cl22-43.hnpj 


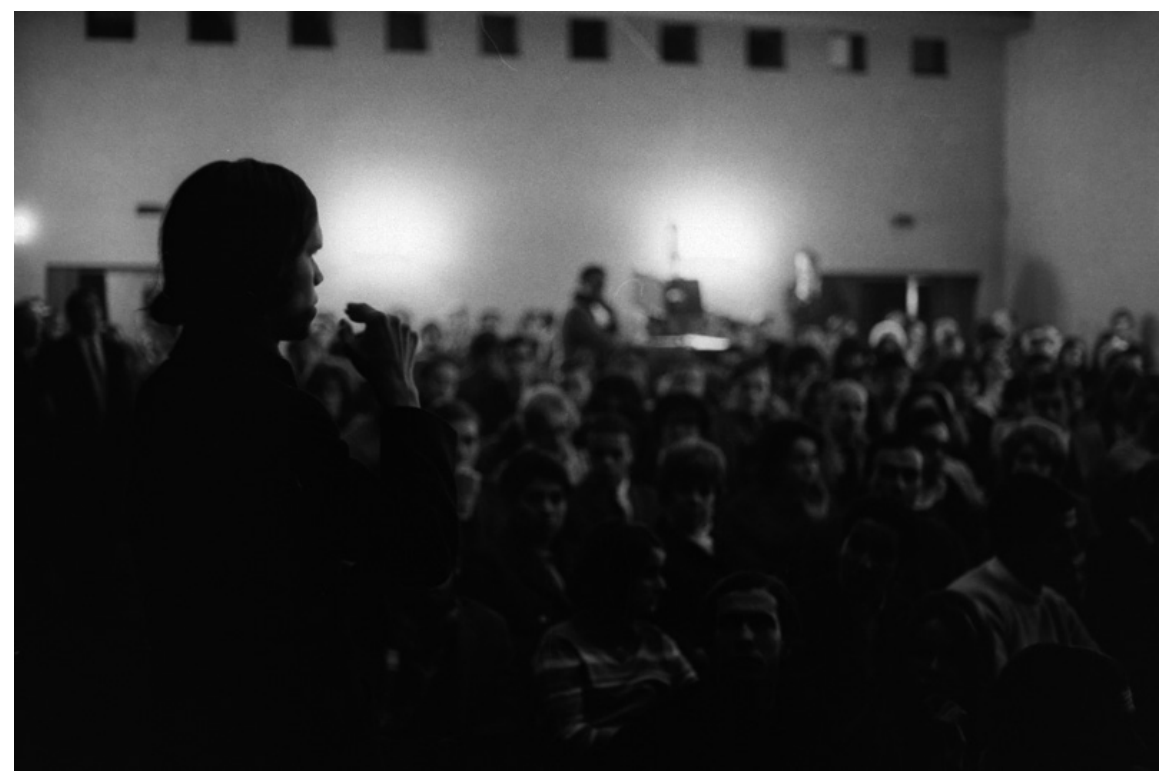

Figura 1. Jaime Barrios en la Cineteca de la Universidad de Chile en 1968 Fото: Marcelo Montealegre.

Esta FOTO DE Marcelo Montealegre sugiere la intensidad de las discusiones que suscitó la proyección de la película experimental de Jaime Barrios, ${ }^{1}{ }^{H o-}$ menaje a Nicanor Parra, en la Cineteca de la Universidad de Chile en $1968 .^{2}$ El estreno chileno de este filme de 44 minutos -realizado unos meses antes, durante una memorable visita de Parra a Nueva York- tuvo cierta resonancia pública en Santiago, a juzgar por las reseñas del polémico filme en la prensa (Ver Gilroy; "Film protagonizado..."; "Otra muestra..."; "Pesadilla con artefactos poéticos..."). ${ }^{3}$ La pinta del "joven productor de cine llamado "un-

1 Agradezco las conversaciones con los otros participantes del dossier sobre Jaime Barrios organizado para la revista chilena de cine La Fuga (en prensa), Sebastián Figueroa, Jessica Gordon-Burroughs y José Miguel Palacios, por su atenta lectura de este trabajo. Las conversaciones con el fotógrafo chileno Marcelo Montealegre desde el 2014, colaborador de Jaime Barrios en NY por muchos años, han sido una referencia continua en mi aproximación al cine de Jaime Barrios.

2 Marcelo Montealegre produjo un extraordinario registro fotográfico de la proyección y las actividades de Barrios en la Cineteca en 1968. Le agradecemos a Montealegre el permiso para reproducir aquí esta y otras fotos.

3 Las reseñas de 1968 mencionan la duración de 55 minutos de la película en b/n filmada en 16mm, aunque la copia depositada en la FMC dura 44 minutos, lo que lleva a suponer que hubo distintos cortes del mismo. De acuerdo con la reseña aparecida en El Siglo (8-VIII-68) la película también 
derground"" (según lo describe uno de los reseñistas) no pasó desapercibida: el pelo largo, los "lentes de hippie" y otras insignias del desenfado iconoclasta de un realizador identificado con los estilos de vida del ambiente contracultural neoyorquino y las formas nuevas, no-partidistas, de un activismo radical.

Unos años después de aquel estreno, durante una segunda visita de Barrios a la Cineteca de la Universidad, en 1971, la periodista Amanda Puz de la revista Paula se refiere con cierta empatía a los escándalos suscitados en Chile por las proyecciones de sus películas experimentales (Puz). Primero fue el Homenaje, donde varios de los participantes -incluido el maestro Parra- fumaban yerba en pantalla; luego, el happening nudista de El descubrimiento de América, donde actuó la coreógrafa y bailarina Carmen Beuchat, otra figura fundamental del grupo de performeros latinoamericanos con quien colaboraba Barrios en Nueva York. Sobre la proyección de El descubrimiento de América -de la que lamentablemente, al parecer, solo quedan trozos del negativo o descartes en la Biblioteca Pública de NY- Amanda Puz señala lo siguiente:

Algunos de los espectadores -como tres- se salieron asqueados y ofendidos. Se exhibía una de las películas del chileno Jaime Barrios -El descubrimiento de América- y el empiluchamiento en la pantalla era colectivo. La cámara parecía haber filmado improvisaciones: jóvenes latinoamericanos -algunos chilenos- al parecer amigos, están juntos, hablan inglés y español tan confusamente que se entiende apenas (se supone que el sonido es malo, en parte), se desvisten, hacen el amor. Sin inhibiciones, lentamente, no obviando los detalles. El camarógrafo filmó paso a paso a una pareja haciéndose el amor, de principio a fin; una alegre ducha colectiva, los primeros escarceos y la relación sexual entre dos lesbianas. $(42)^{4}$

La nota-entrevista publicada en la revista Paula registra las reacciones que generó el nudismo de la película desde la animada perspectiva de Amanda Puz, quien entre líneas comenta sobre varios aspectos polémicos de la factura del filme: la improvisación, la mezcla lingüística y el estilo muy poco convencional de Barrios en la coordinación de esa energía performática que recorre los cuerpos en la escena. La filmación misma como modo de propiciar un happening, se puede añadir. Al preguntarse luego sobre la imprevista función política que Barrios le asigna a la acción cinemática, Amanda Puz anticipa algunos temas que me interesa elaborar en este ensayo:

se mostró en el Centro de Cultura Checa y en el Teatro Municipal de Las Condes en Santiago. Agradezco a Claudio Soltmann el envío de las reseñas publicadas en la prensa chilena de la época. 
¿Y qué dicen sus amigos chilenos que abogan por el cine comprometido? Que en sus películas no hay política. "Pero si el sexo es político", es la instantánea respuesta [de Barrios]. "Se empieza por el sexo y se termina cuestionando todo lo demás, hasta la liberación". (42)

La respuesta de Barrios explica la incomodidad que generaban el nudismo y el sexo explícito en El descubrimiento de América, en términos de una reflexión bastante elaborada que sacude las fronteras normativas entre espacios públicos y privados, representación y vida. En su discurso resuenan los giros sesentistas sobre las pulsiones revolucionarias del deseo - bajo la prioridad de un afecto que articula "eros" y "revolución"- en un tono que recuerda, por ejemplo, el debate entre Norman O. Brown y Herbert Marcuse a raíz de la publicación del influyente libro Love's Body de Brown en 1966 y de la segunda edición de Eros y civilización de Marcuse aquel mismo año. Lo menciono aquí para dar una idea del tipo de discusión que motivaba al cineasta y para apuntar también a los debates contraculturales que acompañaron la particular inflexión del cine expandido que Barrios practicaba a fines de los sesenta; un cine que subvertía los límites convencionales entre arte y vida.

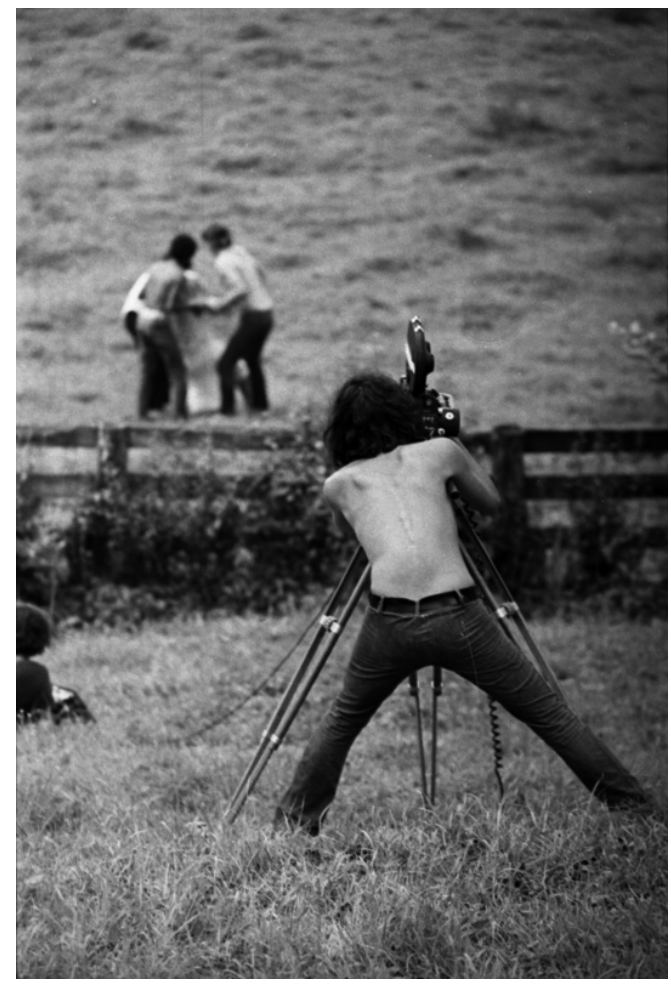

Figura 2. Jaime Barrios filma Virginia Cows ( ${ }_{\mathrm{i}} 1970$ ?)

Fото: Marcelo Montealegre. 
En efecto, Barrios hizo varias películas experimentales a fines de la década del sesenta de las cuales solo ha sobrevivido una: Homenaje a Nicanor Parra. La película se mostró en la Cineteca bajo el título de Parra+Nemesio+Peña+Kitty. Una pesadilla en celuloide; pero la única copia que se conoce, ubicada en los archivos de la Film-Makers' Coop de Jonas Mekas (aún sin restaurar ni digitalizar) se registra como Homage to Nicanor Parra. La película se proyectó en la Cineteca junto a Chilenos en Nueva York (ن1967?) y Film Club (1968), también dirigidas por Barrios, dos documentales de temática social cuya coincidencia con el cine directo y el reportaje nos da una idea de la heterogeneidad de estilos fílmicos que convergen en el trabajo de este cineasta incluso durante aquella etapa inicial de su mayor intensidad experimental. ${ }^{5}$

El Homenaje se filmó en un apartamento de Nueva York, probablemente la residencia personal del pintor chileno Nemesio Antúnez, amigo de Parra y vecino de Barrios en el East Village de Manhattan. Para entonces, Antúnez ejercía el cargo de Agregado Cultural de la Embajada de Chile en los Estados Unidos, lo que explica, según veremos luego, su reacción al filme. La película, hecha en ocasión de la visita de Nicanor Parra a Nueva York en 1968, consta de dos secuencias. La primera alterna entre el registro de la lectura de varios poemas y una entrevista entrecortada que le hace a Parra el performero y bailarín venezolano, Rolando Peña, mientras una tercera participante, Kitty, observa en silencio o interviene entrecortadamente en inglés. Hacia el final de esta primera secuencia, los participantes fuman marihuana ante la cámara motivando así el salto brusco a la fiesta sicodélica y rocanrolera de la segunda secuencia.

El Homenaje está filmado desde los ángulos y variaciones del zoom de una Bolex en posición fija, sin mucha edición de imagen, con una banda sonora más editada, aunque su asincronía perturbó a varios espectadores del filme en 1968, tal como señalan un par de reseñas. Se trata, en efecto, de una escena contracultural, un happening propiciado por la acción fílmica. De ahí la importancia de la improvisación durante el rodaje (por ejemplo, el nombre de Kitty se asocia pronto con la entrada a cuadro de un gato en un pun bilingüe posiblemente asociado a un importante texto de los inicios de Parra como escritor, el enigmático relato titulado "El gato en el camino"). De la improvisación se desprende también la factura informal de esta película, que se escabulle entre las fronteras genéricas, socavando las clasificaciones, los marcos más reconocibles del emergente cine experimental y el documentalismo de aquellos años. Para darnos una idea de la divergencia que representa

5 La nota de Amanda Puz incluye también comentarios sobre la recepción de estas otras dos películas de Barrios en Chile: Chilenos en Nueva York y Film Club. 
esta película en un contexto latinoamericano, podríamos ubicarla en diálogo con algunos de los trabajos incluidos en la valiosa Colección Experimental de la Cineteca Virtual de la Universidad de Chile, entre las primeras películas de Raúl Ruiz, por ejemplo, el legado documentalista de Joris Ives, o los ejercicios experimentales de Chaskel y Humberto Ríos en Érase una vez (1965), cuyo extraordinario montaje animado de los dibujos de V. de Girolamo con música de Gustavo Becerra es, como el filme de Barrios, una aproximación cinemática a la relación entre poesía y política; aunque el montaje, la música y la referencia al régimen de las artes plásticas en el cortometraje de Chaskel y Ríos comprueban un reclamo de autoridad estética contra la cual interviene Barrios en su iconoclasta película. ${ }^{6}$

Conviene considerar también la relevancia del concepto de cine expandido en este abordaje al cine experimental de Jaime Barrios. El concepto, derivado de distintas prácticas y discusiones sobre la expansión de los límites del objeto cinemático, comienza a elaborarse a mediados de los años sesenta tras la publicación de las notas de Jonas Mekas sobre la "visión expandida" del cine underground y artefactos que trastornaban la percepción y los hábitos del consumo de cine (Jacobs y Mekas). Ken Jacobs considera algunas instancias de estas prácticas bajo el neologismo de paracine (ver Collado Sánchez) al contraponer las prácticas expansivas a los dos modos instituidos de hacer cine, ya fuera como un producto industrial, en los regímenes del entretenimiento, o como "obra" de cine-arte, en los circuitos alternativos. El simposio que siguió al festival de cine expandido en 1965 (donde participaron Jacobs, Smith y Warhol, entre otros) -cuyas actas fueron publicadas en un número especial de la revista Film Culture (1966) que dirigían los hermanos Mekas en NY- elabora la discusión sobre la expansión de la experiencia cinemática mediante la construcción de dispositivos multimediáticos y tecnologías que transformaban los principios básicos de reconocimiento y recepción del objeto fílmico (proyecciones en pantallas múltiples, shadow play, intersecciones de escena teatral y espacio fílmico, cine-danza, cine-poesía, etc.). De este modo, las discusiones sobre la expansión en el cine anticipaban las dimensiones "interdisciplinarias" de las instalaciones y ambientes que R. Krauss ("Sculpture in the Expanded

6 La Colección Experimental de la Cineteca Virtual de la Universidad de Chile contiene filmes que ejemplifican las corrientes del cine chileno de aquellos años. Además de los trabajos de Raúl Ruiz y Pedro Chaskel y Ríos, la Colección Experimental incluye películas de Helvio Soto, Miguel Littín, Carlos Flores del Pino, y el influyente documental Valparaíso de J. Ivens, con guion de Chris Marker. 
Field") identificó unos años después con el "campo expandido" del arte, en su artículo sobre la escultura, referencia clave en los estudios actuales de la interdisciplinariedad en la cultura visual.

Desde sus inicios, las discusiones sobre la expansión de la mirada (y de la escucha) en el audiovisual, destacan tres aspectos. Primero, la referencia a la "expansión de la conciencia" y la percepción como un objetivo de prácticas experimentales que, como en el caso de la marihuana en el Homenaje, podían implicar un estímulo psicoactivo. Segundo, la referencia a la hibridación del soporte y la combinación de tecnologías como modo de descentralizar y visibilizar la materialidad del aparato cinematográfico (y dislocar así los hábitos naturalistas del consumo del cine como producto o mercancía). ${ }^{7}$ Tercero, la referencia a la dimensión performática de acciones mediáticas o happenings propiciados por la producción fílmica en escenas que implicaban frecuentemente un trabajo con otras prácticas, como la poesía y la danza, así como con otros medios de la sociedad del espectáculo y el consumo. Este aspecto es particularmente importante en el caso de Barrios, cuyo cine, si bien opera dentro del marco de los soportes y dispositivos reconocibles del aparato cinematográfico, está potenciado por la interacción performática. Como veremos en este ensayo, en el caso del Homenaje a Nicanor Parra, esa dimensión realizativa o performática del filme supone un trabajo con la poesía. La dimensión expansiva de su cine, muy ligado al habitus contracultural, conlleva una apuesta por la improvisación que permite distinguir el cine de Barrios de otros objetos fílmicos más convencionales de su época.

A su vez, el alcance realizativo de la experimentación en Homenaje despliega una relación singular entre cine y política. Las proyecciones en la Cineteca de la Universidad de Chile en 1968, y luego en 1971, permiten ubicar los trabajos relativamente desconocidos de Barrios en el contexto de las polémicas sobre experimentación y política que transitan el cine latinoamericano de los años sesenta y que organizan todavía hoy los recortes de su archivo e historiografía. En ese sentido, el volumen colectivo editado e introducido recientemente por Mariano Mestman (Las rupturas del 68) es un punto de referencia inicial, no solo por el rigor de varias de sus contribuciones, incluida la extensa introduc-

7 Este es el aspecto que Youngblood enfatiza en su libro Expanded Cinema, donde la expansión se refiere casi exclusivamente a la intermedialidad en términos tecnológicos. Aunque esta es una referencia fundamental en la discusión sobre el cine expandido, Youngblood pasa por alto los antecedentes en el underground, acaso por un interés más exclusivo por la historia de la tecnología y sus efectos en la percepción. 
ción del propio Mestman, sino también por el modo en que traza una especie de mapa cognitivo de las operaciones conceptuales y estrategias críticas en el campo de los estudios de cine latinoamericano de aquel periodo. La introducción de Mestman resume los interrogantes que dieron pie a su selección de trabajos a partir de las tensiones o contradicciones entre distintos modos de comprender el concepto de "vanguardia", ya sea en términos políticos, ligados a una izquierda militante, o en términos estéticos, ligados a diversas poéticas (frecuentemente divergentes) de la experimentación. Como en varios de sus trabajos anteriores -incluida entre ellas su colaboración con Ana Longoni ( Del Di Tella a "Tucumán arde") sobre la cultura visual argentina (Tucumán arde y el Instituto Di Tella) - la estrategia de Mestman en este volumen colectivo sobre las "rupturas" del 68 supone cierto cuestionamiento de un consabido esquema que contrapone "militancia"y "experimentación estética".

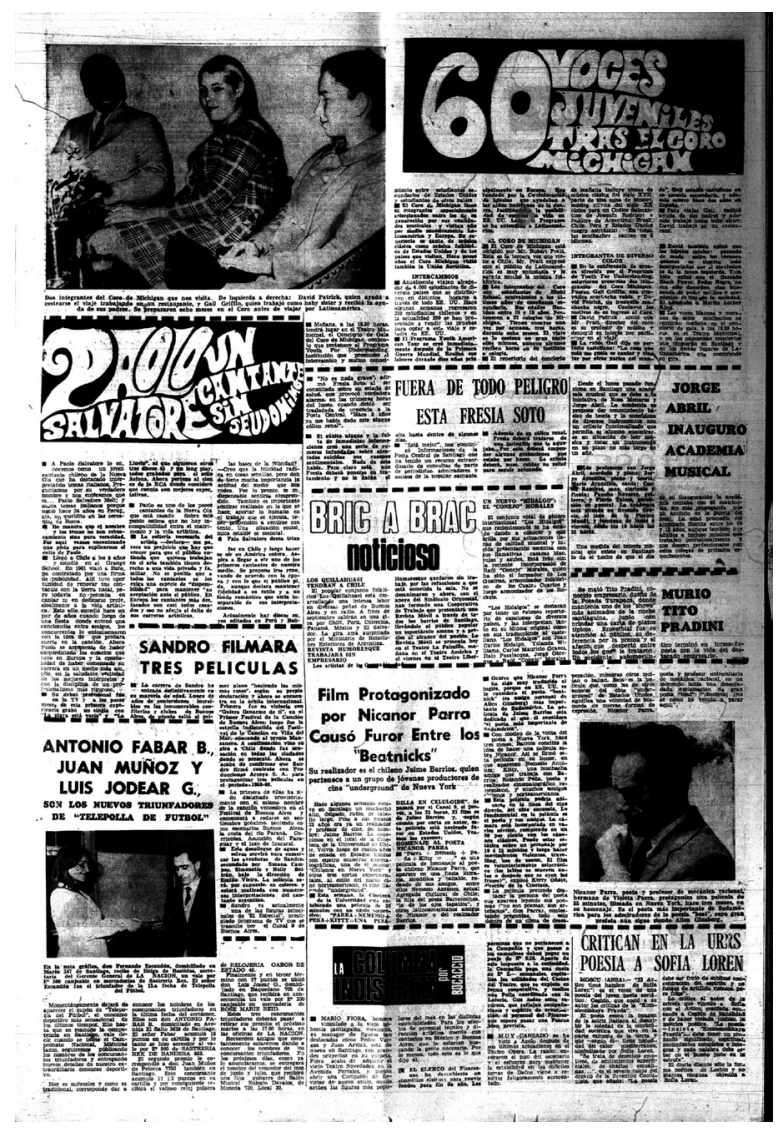

Figura 3. Reseña (anónima) en el periódico El Siglo, órgano del Partido Comunista Chileno 
La disputa tiene una historia que se remonta probablemente a los debates sobre el realismo social y las purgas estalinistas de mediados de la década de 1920; purgas que estimularon luego las polémicas decisivas entre Lukács y Brecht (y Benjamin), durante los años 1930 (Adorno et al.). La disputa toca sin duda la cuestión de la autonomía de los campos y los reclamos de especificidad (incluso de especificidad política, como argumentaba Adorno) del arte, la música y la literatura. En un contexto latinoamericano anterior a los debates marxistas, también había sido clave la cuestión de la autonomía contradictoria de la literatura y su función política, ejemplificada por la dinámica entre las "dos patrias" de José Martí, escritor-político por excelencia, de cuyo discurso proviene, por cierto, el título La hora de los hornos (1968) de Fernando Solanas y Octavio Getino, ícono del documental militante en el continente. En el contexto radicalizado de los años sesenta, las propuestas del "tercer cine" y del "cine imperfecto" (ambas de 1969) participan del proyecto del compromiso político y de la "descolonización del cine", articulaciones de una vanguardia militante que bien pueden leerse como correlatos ideológicos del proyecto de un cine popular-nacional alternativo, tal como sugiere Gonzalo Aguilar ("El pueblo como lo real...") en su trabajo sobre la consolidación del "nuevo cine" durante el Primer Encuentro de Cineastas Latinoamericanos celebrado en el Festival Internacional de Viña en 1969. Allí la salida crítica de Raúl Ruiz, como ha demostrado Iván Pinto ("Crítica y crisis en el Nuevo Cine"), dividió polémicamente las aguas entre el tipo de militancia que dominó en el Primer Encuentro y un acercamiento alternativo a la política desde las prácticas de un cine identificado como arte y experimentación.

Si bien los investigadores del periodo reconocen la tensión entre militancia y experimentación estética como un estímulo decisivo del cine (y de su deriva historiográfica), se ha prestado poca atención al papel desestabilizador que otro cine experimental inscribe en el drama más visible de aquellos debates y contradicciones. Digamos que este otro cine de los años sesenta subvierte tanto los esquemas evidentes del cine militante como el marco del llamado cine de arte o cine de autor. Lo que a su vez posibilita una aproximación diacrítica a los dos extremos o categorías habitualmente contrapuestas. La hipótesis básica es esta: desde la factura (y fractura) conceptual de la imagen, el cine experimental de los años sesenta desarma la contraposición entre militancia y cine de arte en una trayectoria que potencia formas alternativas de pensar la política. 
Este es el caso del Homenaje a Nicanor Parra de Jaime Barrios y del Diálogo con el Che del puertorriqueño José Rodríguez Soltero, dos filmes realizados en 1968. Ambas películas entablan un diálogo inexplorado entre el cine latinoamericano y las vanguardias del underground neoyorquino de los años sesenta. Diálogo con el Che de Rodríguez Soltero es una dramatización de la conocida captura fotográfica (por Freddy Alborta) del cadáver del Che en Bolivia, que inspiró luego el magnífico ensayo fílmico El día que me quieras (1987), realizado por Leandro Katzen en Nueva York -sobre el cual ha escrito ampliamente el propio Mestman ("La última imagen sacra...")-.8 Está claro que Mestman no pudo haber conocido las películas de Barrios o de Rodríguez Soltero cuando reunió los artículos de su volumen sobre 1968: las películas solo existen en celuloide, depositadas en un archivo de difícil acceso en Nueva York. ${ }^{9}$ Pero no está demás preguntarse qué efecto tienen estas películas experimentales en el marco de la discusión sobre las vanguardias de 1968 y las políticas de la experimentación.

Ahora bien: ¿será todavía necesario preguntarse -a estas alturas del debate sobre la geopolítica del latinoamericanismo y la crítica de sus categorías identitarias/territoriales- si son o no son "latinoamericanas" estas dos películas producidas en NY? El hecho de que Homenaje a Nicanor Parra se realizara allí - como toda la obra de Barrios, quien vivió en NY desde 1963 hasta su muerte en 1989- en diálogo con las corrientes contraculturales y minoritarias de la ciudad, incita a considerar la relación entre Barrios y otras figuras latinas del underground neoyorquino como el mismo Rodríguez Soltero. Esto tiene por lo menos tres consecuencias. Primero, nos presiona a considerar la dislocación de las categorías territoriales -ya sea de procedencia o de identidad cultural- que regulan el recorte del archivo, sus inclusiones y exclusiones en los mapas con que opera la historiografía del cine latinoamericano. Segundo, la aproximación a estos materiales con-

8 El trabajo de David Oubiña ("El profano llamado del mundo") analiza las tensiones entre diversas inscripciones fílmicas de la figura del Che en el cine como un modo de abordaje a la contradicción mayor entre vanguardias, poéticas y políticas. Al parecer Oubiña tampoco conocía la película de Rodríguez Soltero.

9 El Che de Rodríguez Soltero - proyectada en Cannes, en la Cinematheque neoyorquina de Jonas Mekas y en la Berlinale en 1969, bajo el título de Che is Alive!- está finalmente en proceso de restauración. La película de Barrios sobre Parra estrenada en la Cineteca de la Universidad de Chile en 1968 sigue pendiente en los archivos de la Film-Makers' Coop de Nueva York, aún sin planes muy definidos de restauración. Sobre la Coop ver Serra y Ramos ("Entrevista a M.M. Serra..."). 
tribuye a explicitar y a problematizar la pretensión de homogeneidad que generalmente domina en las historias de una contracultura norteamericanaglobal, cuya identificación reducida con unas pocas figuras ejemplares -Mekas, Smith, Warhol o Brakhage- ha invisibilizado las intersecciones interculturales y las tensiones internas, frecuentemente racializadas, de la cultura audiovisual del underground. Esta es la limitación, por ejemplo, del "canon" underground establecido por Parker Tyler en 1969 (Tyler). Por último, la particular inflexión política del cine de estos directores latinos o latinoamericanos de NY lleva a repensar el marco más bien estetizado en que la experimentación del underground ha sido habitualmente conceptualizada y contenida. Además de los filmes de Barrios y los trabajos de José Rodríguez Soltero me refiero también a la presencia notable de otros cineastas como el chileno Juan Downey, el argentino Leandro Katz o el brasileño Helio Oiticica, entre otros que también coincidieron en el mundo que habitaba Jaime Barrios en el East Village de Nueva York. ${ }^{10}$

En el habitus divergente de estas redes de sociabilidad contestataria, el Homenaje a Nicanor Parra, inspirado por el evento de la visita del poeta a Nueva York en 1968, remite a una dimensión literaria de los debates sobre la experimentación. Al ubicar la lectura de los antipoemas de Parra en una escena contracultural, Barrios reinscribe la relación entre poesía y cine que desde las vanguardias históricas había sido un empalme recurrente, paradigmático, en el pensamiento sobre (o desde) la experimentación. ¿Qué supone la persistencia de la voz (y de la letra) poética en aquel contexto contracultural? ¿Qué nos dice el filme de Barrios sobre la relación compleja entre el cine y la poesía, sobre el papel de la poesía no meramente como un tema fílmico sino como un horizonte o modelo de innovación?

Aunque no puedo extenderme aquí en una discusión general sobre la importancia de la poesía como modelo de experimentación en diversas prácticas estético-políticas de la modernidad, en el contexto de este trabajo sobre el Homenaje a Parra cabe al menos recordar tres genealogías de las

10 Los primeros trabajos sobre la participación latina en el underground emergen de las discusiones LGBT y la genealogía cuir de la contracultura de hace aproximadamente una década. Ver Suárez (Bike Boys); Negrón Muntaner; y Cruz Malavé (Queer Latino Testimonio). Esta genealogía estimuló primero el revival (y restauración) de las primeras dos películas de Rodríguez Soltero y el reconocimiento de Mario Montez (Ver R. Gregg; Suárez "Jack Smith..."; Cruz Malavé "Between Irony and Belief..."; y Negrón Muntaner; y, más recientemente, sobre Hélio Oiticica en Nueva York, Aguilar "Nota sobre Helio Oiticica..."; Suárez "Jack Smith..."). 
discusiones sobre cine y poesía legadas de las vanguardias históricas y sus resignificaciones en la década del sesenta. Me refiero, primero, a las reflexiones sobre el carácter figurativo de la imagen en los trabajos fílmicos y ensayosmanifiestos de Buñuel, Artaud y Cocteau. La llamada Trilogía de Orfeo de Cocteau inscribe las modulaciones de la relación entre cine y poesía a lo largo de varias décadas, lo que permite una perspectiva histórica ante la temprana identificación del cine experimental con la economía figural del inconsciente y las figuraciones del poeta como héroe experimental. Una segunda genealogía de la discusión sobre poesía y cine se articula en el trabajo contundente de Pasolini sobre "cine de poesía", crítica del trabajo fílmico y teórico de los surrealistas, especialmente de la prioridad asignada al símbolo freudiano en las primeras películas de Buñuel. La propuesta de Pasolini, imbuida por una discusión semiótica, traslada la inscripción figural de la imagen onírica a una consideración más amplia sobre la desarticulación psíquica del sujeto burgués de la posguerra en el cine de autores como Godard y Bertolucci (o Pasolini mismo). Su concepto del cine de poesía, opuesto esquemáticamente al cine de prosa (que defendía Éric Rohmer) está motivado por la cuestión de las formas de subjetivación y el interés particular de Pasolini por el discurso indirecto libre en el cine y la literatura.

La tercera genealogía, más relevante al Homenaje de Barrios, se ejemplifica en una serie de intervenciones y coloquios sobre cine experimental y poesía consignados en la revista Film Culture, fuente valiosa para la historia de las ideologías y del habitus del cine underground neoyorquino, donde la poesía era un punto de referencia constante. ${ }^{11}$ Más próximas a Barrios en términos temporales e ideológicos, las discusiones en Film Culture ubican la relación con la poesía en el contexto de un cine puntualizado por diálogos interdisciplinarios que ampliaban -en la práctica de los happenings- los soportes sinestésicos y conceptuales tanto del audiovisual como de la poesía misma.

Para los efectos de este ensayo sobre una película prácticamente desconocida de Barrios, conviene destacar el ambiente en que se produce el Homenaje a Parra durante la visita del poeta chileno a Nueva York en 1968. Tras el lanzamiento de la edición de Poems and Antipoems en 1967, Parra viajó a Nueva York invitado por el Poetry Center de la Young Men's-Young Women's Hebrew Association a participar en un recital compartido con el poeta pakistaní Zulfikar Ghose y el

11 Véase, por ejemplo, "Poetry and Film. A Symposium", con la participación de Maya Deren, Dylan Thomas, Arthur Miller, Parker Tyler y otros en Film Culture (1963). 
polaco Czeslaw Milosz (ver reseña en el New York Times 1968). Unos meses antes del recital, New Directions - una de las principales editoriales de la vanguardia norteamericana- acababa de publicar una segunda edición de la poesía de Parra con traducciones de William Carlos Williams, Thomas Merton, Allen Ginsberg y Lawrence Ferlinghetti, entre otras figuras decisivas de la renovación poética de aquellos años (Parra Poems and Antipoems). Esto puede darnos una idea de las redes de circulación internacional de la poesía de Parra y de su relieve en el campo disputado de la poesía chilena, donde representaba ya una alternativa a la autoridad poético-política instituida en torno a la épica revolucionaria del Canto General (1950), referente indiscutible de la poesía comprometida. De ahí que no sea nada casual que Barrios (como cineasta) se aproxime con entusiasmo a la figura alternativa de Parra en 1968: su aproximación implicaba una toma de posición iconoclasta ante los debates sobre política y experimentación que puntualizaban también el campo cinematográfico en que se movía Barrios. ${ }^{12}$

Cuando se filma la película en 1968, la afinidad de Parra con la poesía beat norteamericana, horizonte literario de los movimientos contraculturales, era reconocida tanto en los Estados Unidos como en Chile. El antipoeta sostenía amistad y correspondencia con Allen Ginsberg (quien había pasado una temporada en Chile durante sus travesías suramericanas en 1960), así como con L. Ferlinghetti, poeta, editor y gestor beat de City Lights -la casa editora y librería fundada por Ferlinghetti en San Francisco- que publicó la primera edición de los Antipoems en 1960. Estos datos básicos ayudan a situar la relevancia de los artefactos (tal como Parra llama a sus poemas en el filme) en el ambiente y debates formativos del cineasta chileno del underground. La denominación misma del artefacto aúna poesía y cine experimental en la propuesta de una crítica radical del objeto artístico (en tanto poema o filme) mediante una expansión (o abolición) de las fronteras del sujeto estético: gesto radical que comprobamos tanto en los antipoemas de Parra como en la película que le dedica Jaime Barrios en Nueva York.

12 Sebastián Figueroa me ha recordado que la apuesta de Barrios por Parra en 1968 no impide que también se aproximara a Neruda. De hecho, el último proyecto de Barrios antes de su muerte en 1989 fue un proyecto colaborativo titulado Neruda en el corazón (1993), idea original de Barrios para un filme terminado luego por Gastón Ancelovici y Pedro Chaskel. En su trabajo para el dossier-Jaime Barrios de La Fuga sobre "Los documentales políticos de Jaime Barrios" (mimeografiado), Figueroa señala que el proyecto sobre Neruda es un ejemplo del giro de Barrios hacia el género del documental político o militante a partir de fines de los años 1970, durante los cuales Barrios estaba plenamente dedicado al trabajo con varias organizaciones de la solidaridad internacional chilena. 
Ahora bien, todo esto hace impostergable una pregunta sobre la relación entre poesía y cine en el plano de la organización formal de los artefactos. Es decir, si reconocemos el peso que tiene la forma (o significación) como materia en que se imprimen las mediaciones y pugnas por la autoridad en un campo cultural (ya sea literario o audiovisual), resulta entonces necesario considerar las dimensiones formales en la intersección de la escritura poética y la estructura fílmica. Luciano Piazza ("5 encuadres de los 6 o neoyorquinos") ha sugerido incluso un paralelo entre la informalidad de los antipoemas y el estilo fílmico del Homenaje de Barrios. Si seguimos la vía de esa interpretación homológica, acaso sería posible constatar un paralelo entre la estructura discontinua de la película y los rasgos formales de la innovación antipoética de Parra. Me refiero - para dar solo un par de ejemplos bastante conocidos- a la articulación paratáctica de poemas como "Versos sueltos" e "Ideas sueltas" de Versos de salón y La camisa de fuerza, respectivamente, poemarios incluidos en Obra gruesa (1969), de donde proviene buena parte de los poemas leídos por Parra ante la cámara:

Un ojo blanco no me dice nada.

Hasta cuándo posar de inteligente.

Para qué completar un pensamiento.

¡Hay que lanzar al aire las ideas!

El desorden también tiene su encanto.

La "soltura" que califica el título de estos "Versos sueltos" remite a la aparente informalidad de un tono coloquial que se desata de cualquier modelo canónico de la elocuencia o "inteligencia". Pero el título también se refiere al lugar "suelto" de cada verso (o "idea") en la fragmentaria lógica del poema en tanto unidad o estructura de sentido. La fragmentación ahí no pasa por el drama de una ruptura sintáctica (como ocurría en el Vallejo de Trilce, o en la Residencia en la tierra y la Tentativa del hombre infinito de Neruda). En cambio, los poemas de Parra son de sintaxis y tono desdramatizado, propensos al lugar común -lo que J. Ortega llama "las palabras de la tribu" - aunque enseguida hay que notar que Parra intensifica la desarticulación entre las partes y las ficciones sociales del "todo" y problematiza así, de antemano, cualquier hábito de idealizar la "oralidad" (o el dialogismo) como fundamento de comunidades reales o imaginarias. ${ }^{13}$ En Parra predomina el

13 Sobre las modulaciones e inscripciones del tono en la poesía coloquial, resulta fundamental la Caligrafía tonal de A. Porrúa (Caligrafía tonal). 
tono coloquial de una conversación entrecortada o distraída que complica el ideal de presencia presupuesto por el diálogo orgánico como modelo de comunicación social. La soltura de los versos intensifica el papel de los intervalos al producir un vacío (cognitivo) entre los versos dislocados por una operación acumulativa que si bien roza a veces en la redundancia, no cancela el impulso aleatorio de la escritura poética ubicada en una intersección singular de la elipsis surrealista, la inflexión conversacional y popular de los tonos y el humor iconoclasta de los antipoemas.

Aunque no creo que se pueda reducir la complejidad de esta poesía a los efectos de la parodia, está claro que la poesía de Parra impacta los principios de coherencia, los rituales y las insignias de la elocución poética, impugnando así el tipo de autoridad culturalista, a veces incluso cuasi-religiosa, que la figura del poeta había asumido en la historia chilena y latinoamericana moderna desde José Martí o Gabriela Mistral. Parra es un poeta profano, en el sentido que le da Agamben (Profanaciones) a esta palabra, para referirse no solo a un proceso de desacralización (o desublimación) de las formas -lo que de por sí es bastante frecuente en Parra-, sino también a la apertura de inscripciones heterónomas de la experiencia. En su lúcida aproximación al poeta, William Rowe revive una audaz metáfora de Parra - el poema-ameba- para dar cuenta de la maleabilidad orgánica de una poesía que hasta en sus unidades mínimas se intensifica en el recorrido crítico de sus fronteras o límites constitutivos, subvirtiendo las distinciones "esenciales" entre el "adentro" o el "afuera" de la poesía o del arte. De la deriva anti-institucional de la poesía de Parra también se desprende el acercamiento de Carlos Pérez Villalobos en su ensayo fílmico, Para Parra (2009), valiosa exploración del lugar contestatario del poeta y de la significación de su antipoesía en el campo de las disputas literarias por la autoridad o el capital simbólico.

Así como Parra practicaba una (anti)poesía que disloca y corroe los protocolos lingüísticos y performativos de la institución poética, la película experimental de Barrios apuesta por el devenir de un anti-cine. Esto se desprende de la contingencia de la realización que resulta notable, por ejemplo, en la improvisación (ligada al happening) que disloca la autoridad directorial en varios de sus filmes. Por eso la aproximación formal a los paralelos o analogías entre la forma poética y la estructura fílmica, si bien resultaba sugerente, no explica la fuerza pragmática o performativa que despliegan ahí ambos, el cine y la poesía, en el momento de la impugnación de los regímenes del reconocimiento, donde la designación del valor y de la autoridad cul- 
tural se encuentra habitualmente establecida, cristalizada, en la motivación conativa del estilo o de la disposición figurativa y retórica. Por cierto, Homenaje es un filme relativamente "desestilizado": no hay que buscar ahí una economía de la excepcionalidad distintiva de un cine enfático de su estilo o función estética. A contramano del tipo de cine de autor que exhibe (o "autorreflexiona" sobre...) sus recursos técnicos y formales (ya sea por medio del quiebre narrativo, la audacia del montaje o la dislocación del encuadre) el filme de Barrios reduce el papel prioritario del saber técnico y del estilo cinematográfico a estrategias bastante simplificadas de registro, producción y postproducción. La reducción del aparato formal se da en proporción inversa al peso que cobran los efectos de la improvisación y las inesperadas coincidencias que propicia el happening.

Como señalamos anteriormente, la película consta de dos secuencias, ambas filmadas en cámara fija con tendencia al plano largo (hay un plano secuencia de más de 10 minutos), que captura la lectura de Parra y su conversación distraída con otros dos personajes: Kitty, una joven norteamericana amiga de Barrios (quien solo habla inglés en la película) y Rolando Peña, el performero venezolano que "entrevista" a Parra. Hacia el final de esa secuencia también entra a cuadro el pintor Nemesio Antúnez, quien recita poesía de Parra.
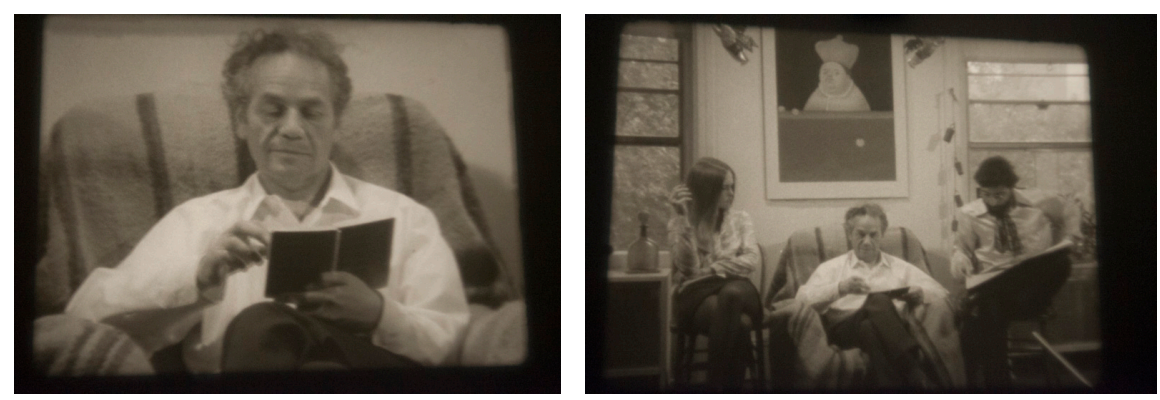

Figuras 4 y 5. Fotos de Homenaje a Nicanor Parra Fотоs: Marcelo Montealegre.

El plano medio de la lectura y de la conversación entrecortada por momentos simula o parodia un encuadre convencional televisivo del géneroentrevista, lo que indica la acción mediática del filme. Para tener una mejor idea de la deriva mediática del encuadre, vale la pena notar que hacia esos mismos años surgen los primeros "talk shows" en la TV, género que evidencia una temprana curiosidad comercial ante la excentricidad pintoresca de 
algunos componentes del underground en "talk shows" como los de Merv Griffin, por ejemplo, quien había entrevistado a Warhol en 1965 y a Ginsberg en 1967. Las variaciones de ángulo o apertura de los encuadres son mínimas, aunque a veces abruptas, sin transiciones elaboradas, según también comprobamos en el corte a la segunda secuencia de la película, donde Barrios instala la Bolex en el interior de una fiesta roquera y sicodélica que incluye a los participantes de la entrevista inicial, incluido el propio cineasta, Barrios, quien también aparece festejando en escena.

Diríamos que se trata simplemente del registro de un happening, si no fuera porque la filmación implicaba la realización (performativa) de esa escena contracultural. Dicho de otro modo, la filmación produce su objeto mediante una acción que cinematiza la presencia de Parra y su lectura de los antipoemas. La cinematización ubica a la poesía (y al poeta) entre otros discursos en un enrarecido ambiente contracultural, lo que explica el subtítulo original de la película en 1968: Una pesadilla en celuloide. La cinematización implica, por un lado, un extrañamiento de la poesía. Pero a la vez inscribe -en la heterogeneidad del plano fílmico- las relaciones de poder entre los distintos discursos, formas y tipos de autoridad cultural que convergen en el happening como lugar heterónomo, mediatizado, de encuentro entre el poeta, el pintor, el cineasta, los performeros y otros. ${ }^{14}$

Para ilustrar el modo en que la acción cinemática desborda las barreras de la representación y subvierte así los límites entre cine y vida, tomemos uno de los aspectos más polémicos del happening propiciado por la filmación: el momento en que varios de los participantes fuman marihuana frente a la cámara, con efectos en el tempo y la organización sensorial, particularmente sonora de la película. En cuanto a la relación entre la marihuana, el LSD y la historia de la experimentación fílmica, baste por ahora señalar que cuando J. Mekas se refiere a la "expanded vision" en una de sus notas inaugurales sobre el cine expandido ("On the Expanding Eye"), el modelo explícito de esa frase es la "expansión de la conciencia" estimulada por los psicoactivos. En la película de Barrios, la alteración de la conciencia resulta de una impro-

14 Las teorizaciones de O. Masotta (La revolución en el arte) y de R. Jacoby ("Contra el happening") sobre el happening como acción crítica en el campo de los medios elucidan el debate político que suscitaron las acciones en la Argentina hacia 1966 y 1967. Karen Benezra ("Oscar Masotta: Materialism and Dematerialization") ubica esos trabajos, incluidos inicialmente en el libro colectivo Happenings, editado por Masotta en 1967, en el contexto más amplio del análisis de la "desmaterialización del arte". 
visación, cuando uno de los participantes, el performero venezolano Rolando Peña, sale de cuadro y vuelve pronto a entrar con un pitillo de yerba. Parra había leído ya varios de sus poemas -"Última hora", "USA donde la libertad es una estatua", "Discurso de sobremesa", "Dime si te molesto con mis lágrimas", "Busque en las alcantarillas", "Sistema solar", "Mala cueva", "Acto gratuito", "Total cero" y "Anciano difícil" - cuando Peña regresa al cuadro y pone a circular el pitillo entre los participantes. Allí no había cuarta pared para contener el humo, lo que enseguida nos lleva a preguntarnos sobre la relación entre la alteración sensorial desplegada en el acto poético y la ontología peculiar de la marihuana como objeto o como técnica de alteración de los estados normativos de la conciencia.

$\mathrm{Al}$ respecto, voy a concentrarme brevemente en un cambio en la banda sonora a partir de la irrupción de la marihuana en el filme. El audio de Homenaje, como notaron varios detractores de Barrios en las reseñas chilenas de la película (Ver Gilroy; "Film protagonizado..."; "Otra muestra..."; "Pesadilla con artefactos poéticos...") había sido problemático desde el comienzo del filme. La banda sonora incluía el sonido directo de la lectura y la conversación durante la primera secuencia, grabada con una Nagra portátil, fuera de sincronía. Si a esto le sumamos las pistas de sonido de calle que Barrios incorpora en su edición, cuyo volumen gradualmente se incrementa -y consideramos además la intervención de otras voces no siempre identificables visualmente- tendremos una idea del quiebre acusmático entre imagen y audio en Homenaje: la desarticulación audio/visual que escinde la unidad espacio-temporal de la imagen (y de la poca "acción" durante la lectura de los poemas) en contrapunto con el sonido urbano introducido en la postproducción. El ruido del afuera fractura los principios naturalistas de un verosímil audiovisual (Chion; Keaton).

La edición sonora expone la poesía a la calle. Esto ocurre precisamente en el momento de mayor reclamo de eficacia ritual de la poesía, mientras Parra lee pausadamente en un espacio interior. Esto nos lleva nuevamente a preguntarnos sobre el lugar que ocupa la poesía (y el poeta) en el heterónomo espacio de este cine. La cinematización de la poesía en la película desestabiliza los protocolos, el régimen de legibilidad poética mediante un gesto iconoclasta que hasta cierto punto es compartido por los antipoemas de Parra y su cuestionamiento de la institución literaria. Pero Barrios va más allá al ubicar la voz del poeta entre ruidos de procedencia callejera que desintegran la voz única (autorial) de la lectura tras la interrupción inducida por la marihuana. 
Poco después de que Peña se levanta y pone a circular el pitillo, se intensifica el ruido y se fragmenta la elocución poética. Esto ocurre primero con la introducción de otras tres voces que leen simultáneamente un poema de Parra en un contrapunto disonante antes del corte brusco que da fin a la primera secuencia. Sin transición lógica alguna, nos encontramos de pronto en otro espacio, una sala de apartamento, donde los mismos participantes de la secuencia literaria aparecen entre otra gente en una fiesta. La figura del poeta queda desplazada hacia el fondo de la profundidad de campo de un plano rocanrolero. Parra no baila. Las pocas veces que la cámara lo capta es al fondo del plano, al margen de la fiesta, que ahora sugieren el repliegue o la desconexión del poeta fiestero y danzarín de "La cueca larga". Se trata, en efecto, de la problemática ubicación del poeta -incluso del iconoclasta antipoeta- entre los nuevos artefactos (el cine mismo) o estilos del ambiente contracultural durante un happening que también nos recuerda los importantes debates históricos de la izquierda sobre el rock-and-roll en varios países latinoamericanos durante la década del sesenta. ${ }^{15}$

Para ubicar mejor la dislocación del poeta durante la fiesta, hay dos detalles de la primera secuencia que conviene enfatizar. Primero, el poema leído a tres voces en el momento de desarticulación sonora de la primera secuencia (luego de la circulación del pitillo) no es otro que "La cueca larga" de Parra:

Voy a cantarme una cueca

Más larga que sentimiento

Para que mi negra vea

Que a mí no me cuentan cuentos.

La referencia a la cueca -género bailable del folclore nacional chileno-, así como el octosílabo en la métrica tradicional de esta copla, explicitan el trabajo de Parra con las formas de la cultura oral. El poemario, publicado bajo ese mismo título en 1958, había sido ilustrado nada menos que por Nemesio Antúnez, participante en el happening de Parra en NY, de quien proviene una de las tres voces trenzadas en la lectura contrapunteada de "La cueca larga" al final de la primera secuencia, cuando los participantes fuman yerba y se fragmentan las voces. No hace falta destacar el contraste evidente entre la cueca como referencia a lo nacional-popular y el espacio sonoro contracultural del rock en esta secuencia que, por otro lado, constata el peso de los debates político-culturales que impregnan la materia sensible y las significaciones históricas del sensorio movilizadas por la cinematización de la poesía.

15 Ver el trabajo de Lúcia Sá sobre Caetano y la izquierda brasileña en 1968. 
Como decíamos, hay un segundo detalle de la primera secuencia que también remite a estos debates político-culturales, pertinentes asimismo a la relación entre militancia y experimentación que nos ha ocupado en este ensayo. La entrevista que le hace Peña a Parra es dispersa. Aunque nunca cobra el vuelo de una conversación, hay una pregunta de Peña que me parece particularmente significativa. En tono grave, "serio", Peña interpela a Parra: "Nicanor, es interesante esa cosa lógico-ilógica, principio de la negación de la negación. Porque entonces yo creo que para nosotros los latinoamericanos que tenemos tantos años de colonización de todo tipo... [sic]. Me gustaría que me dijeras cómo reacciona a estos poemas la gente" (entre 10:37 y 11:52). Parra, indiferente al vocabulario latinoamericanista de izquierda de Rolando Peña (quien ese mismo año había hecho el papel del Che Guevara en la película antes mencionada de Rodríguez Soltero), le responde: "Sí, a esa pregunta se responde con un poema"; y lee enseguida el "Discurso del buen ladrón". La elipsis de Parra ante la pregunta política de Peña es reveladora. El paso de la pregunta a un poema sobre el oportunismo político implica un salto: desvía la pregunta política y muestra la discontinuidad, la fisura de la elipsis entre dos discursos que cohabitan el mismo espacio performativo de la película y de la vida política y cultural.

Esa discontinuidad cobra relieve a la hora de retomar una pregunta que nos hicimos antes sobre el modo en que Barrios - no tan solo Parra- atraviesa transversalmente la contraposición dura, esencializada, entre cine militante y cine de arte, para proponer una salida alternativa a la experimentación como modo de intervención política. El intervalo entre la pregunta interpelativa de Peña y el poema con que le responde Parra interrumpen el orden de la interpelación. La pregunta de Peña en el fondo implicaba ya una interpretación de la "lógica-ilógica" de Parra al identificarla como una consecuencia o expresión (crítica) del colonialismo. La respuesta de Parra es inevitablemente próxima (o contigua) a la pregunta, pero su emplazamiento poético, azaroso (aunque no arbitrario), propone claramente una respuesta poética a una pregunta política. Es decir, lo que está en juego en la cinematización de la poesía es la cuestión de la proximidad problemática entre la poesía y otros discursos; en este caso, un discurso político que intenta someter la interrupción poética (la "lógica-ilógica") a un orden explicativo e ideológico ("colonial"). La cinematización de la poesía no puede entonces reducirse a una evidencia de la lógica poética; la cinematización del acto poético explicita la ubicación de la poesía (incluso sus pugnas), su proximidad a otros discursos y medios, en el espacio heterónomo del cine. 
El papel de la marihuana -cuya intervención improvisada produce una alteración de los sentidos y del tono mismo de la película, hasta el punto del corte brusco de la secuencia literaria antes de los planos de la fiesta sicodélica- resulta clave para entender las tensiones entre la izquierda y la contracultura. Recordemos, por ejemplo, la secuencia de la fiesta contracultural en otra película de 1968, La hora de los hornos, de Fernando Solanas y Octavio Getino, en contrapunto polémico con la fiesta de Barrios. Me refiero al tono moralizante de la voz en off en La hora de los hornos (1968) -su denuncia del ambiente artístico y rocanrolero del Instituto Torcuato di Tella-, donde Solanas y Getino lanzan una crítica desde la izquierda militante al decadentismo y la frivolidad de otra vanguardia inspirada por la cultura $p o p$, el rock y los happenings del Imperio.

Al menos desde la expulsión de Allen Ginsberg de La Habana en 1965 - por fumar marihuana y por decir en una entrevista que deseaba acostarse con el Che-, se complicaron los intentos de mediar entre las "vanguardias" que habían confluido desigualmente en los movimientos contraculturales de los años sesenta hasta que se abre una brecha o fractura irremediable entre las pulsiones experimentadoras y la moral revolucionaria. La carta extensa que Ginsberg le escribe a Nicanor Parra en 1966 -poco después de su expulsión de Cuba tras la conferencia en Casa de las Américas donde Ginsberg y Parra habían compartido en $1965^{-}$es un documento clave para entender la fractura. ${ }^{16}$ La homosexualidad y la marihuana fueron dos aspectos decisivos en los delineamientos dogmáticos del significado de la "vanguardia" y de la disciplina revolucionaria.

Si bien hoy puede parecernos un detalle inocuo, la filmación de la yerba durante un rodaje fechado en 1968, sin mucha edición, tiene que haber causado bastante alarma entre la gente que asistió a la proyección en la Cineteca de la Universidad de Chile a ver la película. Digamos primeramente que el pitillo de marihuana es una "imagen" en la representación que vemos en la pantalla, pero a su vez es un acto que altera gradualmente la estructura de la película. Barrios borra cualquier distinción tajante entre cine y vida. En eso consiste la relación entre su cine expandido y la estrategia del happening, el desborde del objeto fílmico y de su relativa autonomía. Recordemos que

16 En su carta a Parra (20-VIII-1965), Ginsberg menciona la censura de la revista El Puente (muy próxima a la poética beat y a la contracultura) poco después de su expulsión en 1965. En una extensa entrevista posterior, Ginsberg cuenta sobre el viaje a Cuba y las causas de su expulsión (ver Young y Ginsberg). 
entre los personajes que aparecían en pantalla fumando yerba se encontraban Nicanor Parra, poeta encaminado a un Premio Nacional en 1969, y Nemesio Antúnez, quien para entonces todavía ejercía el cargo de Agregado Cultural de la Embajada de Chile en los Estados Unidos. Esto explica en parte algunas de las reacciones que produjo la película en Chile.

Alguna vez habría que hacer una ontología de la marihuana y otras tecnologías de la alteración sensorial y su cambiante relación con las políticas de la verdad y del cuerpo en América Latina. ${ }^{17}$ La dimensión material de esa historia no tendría por qué distraernos del sometimiento complejo de los psicoactivos bajo una lógica de la prohibición y de la guerra contra las drogas, ni tampoco llevarnos a obviar, en otros contextos, la dimensión económica de su pujante producción agroindustrial, o a ignorar el papel que los psicoactivos han cumplido, más allá de los ambientes artísticos o literarios, en los complejos regímenes de la alteración sensorial que suplementan el gobierno de la vida en las sociedades de control contemporáneas. Por cierto, la escena de la marihuana en Homenaje a Nicanor Parra implicaba una violación de la ley de narcóticos tanto en Chile como en Nueva York, algo que Nemesio Antúnez entendió perfectamente cuando intentó censurar la proyección de la película en la Cineteca de la Universidad. Según el testimonio de Marcelo Montealegre, Antúnez estaba preocupado por el desprestigio que la filmación podía causarle a Parra, o a sí mismo, considerando el cargo diplomático que ocupaba. En cambio, de acuerdo con el testimonio de Montealegre (quien acompañó a Barrios en la Cineteca), a Parra lo que sí le molestó fue que lo pusieran en el lugar del juez y le pidieran la aprobación antes de mostrar la película. Según Montealegre, el filme le pareció a Parra una "maravilla", acaso porque Homenaje celebraba la conexión del poeta con un habitus contracultural que desplegaba el rechazo tanto de una moral burguesa como de otra "revolucionaria". Se trata de los efectos de la alteración del cine, cuyo desborde de la representación y quiebre de la autonomía del objeto en el campo de la expansión paradójicamente ubican el filme ante la ley.

17 Ver el valioso libro de G. Labrador Méndez (Letras arrebatadas) sobre las "literaturas del arrebato", donde discute las dimensiones contestatarias o políticas de las drogas en la literatura española de la transición democrática. 


\section{Obras citadas}

Adorno Theodor, Walter Benjamin, Ernst Bloch, Bertolt Brecht y Georg Lukács. Aesthetics and Politics. Postfacio Fredric Jameson. New York: Verso Books, 2007. Impreso.

Agamben, Giorgio. Profanaciones. Trad. E. Dobry. Barcelona: Anagrama, 2017. Impreso.

Aguilar, Gonzalo. "El pueblo como lo real. Una genealogía del cine latinoamericano".

Más allá del pueblo. Imágenes, indicios y políticas del cine. Buenos Aires

y México DF.: Fondo de Cultura Económica, 2015. 179-194. Impreso.

Aguilar, Gonzalo. "Nota sobre Helio Oiticica y Mario Montez". La Fuga 14:

Dossier fosé Rodríguez Soltero (coord. Julio Ramos) (invierno de 2012). http://

www.lafuga.cl/nota-sobre-helio-oiticica-y-mario-montez/565. Web.

Barrios, Jaime. Homenaje a Nicanor Parra. $16 \mathrm{~mm}$. b/n. Única copia disponible en Film-Makers'Coop de NY, 1968. Filme.

Benezra, Karen. "Oscar Masotta: Materialism and Dematerialization". Dematerialization. Art and Labor in Latin America.

Austin: The University of Texas Press, en prensa.

Chion, Michel. Audio-Vision. Sound on Screen. New York:

Columbia University Press, 1990. Impreso.

Cineteca de la Universidad de Chile. Colección Experimental de la Cineteca Virtual de la Universidad de Chile. Archivo fílmico.

Collado Sánchez, Esperanza. Paracinema. La desmaterialización del cine en las prácticas artísticas. Madrid: Trama Editorial, 2012. Impreso.

Cruz-Malavé, Arnaldo. "Between Irony and Belief: The Queer

Diasporic Underground Aesthetics of José Rodríguez-Soltero and

Mario Montez". GLQ: A fournal of Lesbian and Gay Studies 21.4

(Duke University Press, octubre de 2015): 585-615. Impreso.

Cruz-Malavé, Arnaldo. Queer Latino Testimonio, Keith Haring, and fuanito

Xtravaganza: Hard Tails. New York: Palgrave - Macmillan, 2007. Impreso.

Film Culture. "Expanded Cinema Survey y Expanded Cinema Festival (1965)

de Film-Makers' Cinematheque". Film Culture 43 (1966). Impreso.

Film Culture. "Poetry and the Film: A Symposium" (Ed.

Jonas Mekas). Film Culture 29 (1963). Impreso.

"Film protagonizado por Nicanor Parra causó furor entre los

'Beatnicks"'. La Nación (Chile), 7 de agosto de 1968. Impreso.

Gilroy, Harry. "Chilean Physicist Reads His Poetry. Parra in Interview, Talks of

Antipoems and Science". New York Times, 27 de junio de 1968. Impreso.

Ginsberg, Allen. The Letters of Allen Ginsberg. Ed. Bill

Morgan. NY: Da Capo Press, 2008. Impreso. 
Gregg, Ronald. "Fine Vintage. Fashion, Thrift Stores and the Space of Pleasure in Queer Underground Film". Museum of Moving Image Source (abril de 2011). http://www.movingimagesource.us/articles/fine-vintage-20110415. Web.

Jacobs, Ken, Jonas Mekas et al. Intervención en The Discussion on Expanded Cinema. Microscope Gallery, NY. 4 de enero de 2016. https://vimeo.com/150960035. Web. Jacoby, Roberto. "Contra el happening". Happenings. Coord. Oscar Masotta. Buenos Aires: Editorial Jorge Alvarez, 1967. Impreso.

Kane, Brian. Sound Unseen.Acousmatic Sound in Theory and Practice. Oxford: Oxford University Press, 2014. Impreso.

Krauss, Rosalind. "Sculpture in the Expanded Field". October 8.8 (1979): 30-44. Impreso. La Fuga. Revista de Cine (Dossier dedicado a José Rodríguez Soltero. Coord. Julio Ramos. Incluye trabajos y entrevistas de J. Suárez, A. Cruz Malavé, O. Montero, F. Negrón Muntaner, H. Oiticica, G. Aguilar, J. Ramos et al.) (2012). Impreso.

Labrador Méndez, Germán. Letras arrebatadas: poesía y química en la Transición española. Madrid: Devenir Ensayo, 2009. Impreso.

Masotta, Oscar. La revolución en el arte: Por-art, happenings y arte de los medios de la década del sesenta. Buenos Aires: Edhasa, 1974. Impreso.

Mekas, Jonas. "On the Expanding Eye" (1964); "On the Expanded Cinema of Jack Smith, John Vacarro et al." (1965); "On the Expanded Consciousness and the Expanded Eye" (1966); "More on the Expanded Cinema: Emshwiller, Stern" (1966). Movie fournal. The Rise of the New American Cinema 1959-1971. Ed. Gregory Smulewicz-Zucker. New York: Columbia University Press, 2016. 125-127; 230-236; 216-222; 222-224. Impreso.

Mestman, Mariano. "La última imagen sacra de la revolución latinoamericana". Los fantasmas de $\tilde{\mathcal{N}}$ ancahuazú. Ed. Leandro Katz. Buenos Aires: La Lengua Viperina, 2010. Impreso.

Mestman, Mariano (coord.). Las rupturas del 68 en América Latina: contracultura, experimentación y política. Buenos Aires: Akal, 2016. Impreso.

Mestman, Mariano y Ana Longoni. Del Di Tella a "Tucumán arde": Vanguardia artística y política en el 68 argentino. Buenos Aires: Eudeba, 2011. Impreso.

Negrón Muntaner, Frances. Boricua Pop: Puerto Ricans and The Latinization of US Culture. NY: New York University Press, 2004. Impreso.

Ortega, Julio. "Prólogo". Poemas para combatir la calvicie. Nicanor Parra. México D.F. - Santiago de Chile: Consejo Nacional para la Cultura y las Artes Universidad de Guadalajara - Fondo de Cultura Económica, 1993. Impreso.

Oubiña, David. "El profano llamado del mundo". Las rupturas del 68 en América Latina: contracultura, experimentación y política. Coord. Mariano Mestman. Buenos Aires: Akal, 2016. 65-123. Impreso. 
"Otra muestra del 'underground cinema'. Una pesadilla en homenaje a Nicanor Parra". El Siglo, 8 de agosto de 1968. Impreso.

Parra, Nicanor. Poems and Antipoems. Ed. Miller Williams. N.Y.: New Directions Books, 1967. Impreso.

Parra, Nicanor. Versos de salón y La camisa de fuerza. Obra gruesa. Santiago de Chile: Editorial Universitaria, 1969. Impreso.

Pasolini, Pier Paolo. "Cine de poesía". Cine de poesía contra cine de prosa. Pier Paolo Pasolini y Eric Rohmer. Barcelona: Anagrama, 1970. Impreso.

Pérez Villalobos, Carlos. Dir. Para Parra (ensayo fílmico/ documental, 70 min.), 2009. Filme.

"Pesadilla con artefactos poéticos. Happening de Chilenos en NY". Revista del Domingo (El Mercurio), 18 de septiembre de 1968. Impreso.

Piazza, Luciano. "5 encuadres de los 60 neoyorquinos". El jardín de los poetas. Revista de teoría y crítica de poesía latinoamericana. Dossier Poesía en Movimiento (coord. e intro. Ana Porrúa y Julio Ramos) II.3 (segundo semestre de 2016): 124-132. Impreso.

Pinto. Iván. "Crítica y crisis en el Nuevo Cine". Las rupturas del 68 en el cine de América Latina. Coord. Mariano Mestman. Buenos Aires: Akal, 2016. Impreso.

Porrúa, Ana. Caligrafía tonal. Ensayos sobre poesía. Buenos Aires: Entropía, 2011. Impreso.

Puz, Amanda. "Entrevista a Jaime Barrios: Un chileno que se fue y se liberó". Paula 86 (1971): 40-43. Impreso.

Ramos, Julio. "Entrevista a Marcelo Montealegre: Un fotógrafo del underground". La Fuga: Dossier Faime Barrios (en prensa).

Rowe, William. "Nicanor Parra: The Poem as Amoeba". Poets of Contemporary Latin America. History and Inner Life. Oxford: Oxford University Press, 2000. 29-77. Impreso.

Sá, Lúcia. "Caetano: Un caníbal en el exilio". A Contratiempo 10 (Bogotá, 1998): 17-22. Impreso.

Serra, M.M. y Julio Ramos. "Entrevista a M.M. Serra: José Rodríguez Soltero en los archivos de la Film-Makers's Coop de NY". La Fuga: Dossier sobre Rodríguez Soltero (coord. Julio Ramos) 14 (2012). http://2016.lafuga.cl/entrevista-a-mm-serra-joserodriguez-soltero-en-los-archivos-de-la-film-makers-coop-de-nueva-york/559. Web.

Suárez, Juan A. Bike Boys, Drag Queens, and Superstars. AvantGarde, Mass Culture, and Gay Identities in the 1960's. Bloomington: University of Indiana Press, 1996. Impreso.

Suárez, Juan A. "Jack Smith, Hélio Oiticica, Tropicalism". Criticism 56.2 (2014): 295-328. Impreso. 
Tyler, Parker. Underground Film. A Critical History. New

York: Da Capo Press, 1995. Impreso.

Young, Allen y Allen Ginsberg. Gay Sunshine interview with Allen

Ginsberg (1972). N.Y.: Grey Fox Press, 1974. Impreso.

Youngblood, Gene. Expanded Cinema. New York: P. Dutton \& Co., 1970. Impreso.

\section{Conversaciones y correspondencia}

Alfonso Barrios, Marcelo Montealegre, Rolando Peña, Max MacKellar. 